Y-12

NATIONAL SECURITY COMPLEX

\section{Volatile Components from Packing Materials, Rev. 2}

\author{
R. A. Smith \\ Technology Development \\ Applied Technologies Division
}

\begin{abstract}
CAUTION
This document has not been given final patent clearance and is for internal use only. If this document is to be given public release, it must be cleared through the site Technical Information Office, which will see that the proper patent and technical information reviews are completed in accordance with Babcock \& Wilcox Technical Services Y-12, LLC policy.
\end{abstract}

Issue Date: March 2006

Prepared for the (Applicable DOE Funding Office) (Applicable Budget Activity Number)

\section{UNLIMITED DISTRIBUTION}

Prepared by the

Y-12 National Security Complex

P.O. Box 2009, Oak Ridge, Tennessee 37831-8169

Managed by

Babcock \& Wilcox Technical Services Y-12, LLC

for the

U.S. DEPARTMENT OF ENERGY

under contract DE-AC05-00OR22800 


\section{DISCLAIMER}

This report was prepared as an account of work sponsored by an agency of the United States Government. Neither the United States Government nor any agency thereof, nor any of their employees, makes any warranty, express or implied, or assumes any legal liability or responsibility for the accuracy, completeness, or usefulness of any information, apparatus, product, or process disclosed, or represents that its use would not infringe privately owned rights. Reference herein to any specific commercial product, process, or service by trade name, trademark, manufacturer, or otherwise, does not necessarily constitute or imply its endorsement, recommendation, or favoring by the United States Government or any agency thereof. The views and opinions of authors expressed herein do not necessarily state or reflect those of the United States Government or any agency thereof. 


\title{
Volatile Components from Packing Materials, Rev. 2
}

\author{
R. A. Smith \\ Technology Development \\ Applied Technologies Division
}

Issue Date: March 2006

Prepared for the

(Applicable DOE Funding Office)

(Applicable Budget Activity Number)

UNLIMITED DISTRIBUTION

Prepared by the

Y-12 National Security Complex

P.O. Box 2009, Oak Ridge, Tennessee 37831-8169

Managed by

Babcock \& Wilcox Technical Services Y-12, LLC

for the

U.S. DEPARTMENT OF ENERGY

under contract DE-AC05-00OR22800 


\title{
Volatile Components from Packing Materials, Rev.2
}

\author{
R. A. Smith (rox); 576-0615
}

\begin{abstract}
Summary
An outgassing study was conducted on five packing materials, comprising two experiments. These materials comprised 277-4 borated concrete, Borobond 4 concrete, polyethylene bags, silica-filled silicone rubber seals, and silicone foam padding. The purpose was measure the volume of gases which diffuse from packaging materials when sealed in containers. Two heating profiles were used to study the offgassing quantities in a set of accelerated aging tests. It was determined that the concretes contain a large quantity of water. The plastic materials hold much less moisture, with the silicone materials even consuming water, possibly due to the presence of silica filler. Polyethylene tends to degrade as the temperature is elevated and the foam stiffens.
\end{abstract}

\section{Introduction}

A variety of materials are required for safely packaging items for transport or storage. These materials must physically protect components while not causing damage by virtue of their own compositions. According to de Premare, "Sensitive products can begin to deteriorate at just 30\% relative humidity $(\mathrm{RH})$. Many products require a constant $\mathrm{RH}$ of $10-15 \%$ or less for stability and an extended shelf life."

The current study utilizes small samples of ceramic and polymeric packaging materials contained in measured volumes within stainless steel containers. Each container is then attached to a capacitance manometer or "baratron" for on-going measurement of the internal container pressure as the temperature is increased. This method allows determination of the volatiles quantity within the materials, which is most likely moisture but also decomposition products of the some materials. While such moisture is not immediately apparent under ambient conditions, the water contained in packaging is available to diffuse out over long time frames, such as years. To this extent, the maximum or "worst-case" amount can be calculated.

Two heating profiles were used and data calculated in terms of volume of gas at standard temperature and pressure, per material mass, a unit called "specific volume." This quantity was plotted versus time, as was the temperature profile. Visual observation of aged materials was conducted to ascertain obvious changes.

\section{Experimental}

Standard vacuum hardware is used to seal randomly sized specimens of each material (from 0.2 to $5 \mathrm{~g}$ ) in air after they are weighed on a calibrated scale. In most cases, the experiment was repeated, 
but time limitations made this difficult. Additionally a "blank" container was tested under each experimental condition. Each container comprised a 5-inch height stainless steel retort of 1.3" diameter, in which was placed $3.75-4.0$ inch heights of stainless steel block cylinders. This "filler" provided a smaller open volume of which the pressure was measured. This volume could be theoretically estimated, but was experimentally measured by expanding air from each unit into a known volume and measuring the resulting pressures. For experiments, each unit was attached to a pressure measurement system comprising a) and MKS Instruments Type 690A14TRB 10,000 torr baratron; b) MKS 670 signal conditioner electronics for data collection through an Omega datalogger; and c) a computer for data download and storage. The heating steps were conducted in a Despatch LAC 1-67-6 programmable laboratory oven which uses a Protocol Plus microprocessor control. A thermocouple was used to independently track and download the oven temperature to the aforementioned datalogger in concurrence with the pressure data. Upon experiment completion, containers remained sealed until disassembly. Material specimens were re-weighed and stored in labeled plastic bags.

\section{Experimental Procedures:}

I. A thermocouple is incorporated with the baratron such that the pressure is measured as the temperature is increased in a stepwise manner, from ambient to $300^{\circ} \mathrm{F}\left(23-150^{\circ} \mathrm{C}\right)$. Use $50^{\circ} \mathrm{F}$ increments and hold for 120 minutes before each rise. Track outgassing pressure in torr for reporting in specific volume units of $\mathrm{cm}^{3}$ (STP)/g as a function of time and temperature. The planned $300^{\circ} \mathrm{F}$ upper limit was actually recorded at $338^{\circ} \mathrm{F}$.

II. Perform another set of experiments where test materials are held at $180^{\circ} \mathrm{F}$ for two hours; measure pressure over that time frame. Present total offgassing quantity for each material (two specimens each) in specific volume units of $\mathrm{cm}^{3}(\mathrm{STP}) / \mathrm{g}$.

\section{Data and Results}

The data was collected by Omega Hyperware, then downloaded and analyzed using Microsoft Excel. For all materials, charts were produced giving outgassing volume in $\mathrm{cm}^{3}(\mathrm{STP}) / \mathrm{g}$ and temperature in ${ }^{\circ} \mathrm{F}$ from ambient to $338^{\circ} \mathrm{F}$, as a function of time; a text table for outgassing quantity at $180{ }^{\circ} \mathrm{F}$ is provided. The outgassing curves are adjusted for linear rise in background outgassing from the container and filler materials which was measured at a total $19.2 \mathrm{~cm}^{3}$ (STP). A similar background quantity of $4.0 \mathrm{~cm}^{3}(\mathrm{STP})$ is subtracted from the $180^{\circ} \mathrm{F}$ outgas volumes.

I. Experiment 1 (Use $50^{\circ} \mathrm{F}$ increments and hold for 120 minutes before each rise up to $338{ }^{\circ} \mathrm{F}$ ). Figures 1 through 5 are provided for polyethylene, foam, elastomer, Borobond4, and 277-4 Borated concrete. Table 2 provides typical weight changes in specimens before and after the 13 -hour heating experiments to $338^{\circ} \mathrm{F}$ were conducted.

II. Experiment 2 (Reach $180^{\circ} \mathrm{F}$ and hold for two hours; measure pressure over that time). Table 1 summarizes the total quantity of outgassing in this test. Several materials render negative results, indicating an overall reduction in gas due to absorption or reaction with the material at this temperature. The silicone foam and elastomer contain silica filler $\left(\mathrm{SiO}_{2}\right)$ which is known for its reactivity with water. The polyethylene is 
most likely reacting with the oxygen as its chains fragment and degrade. This material was the most obviously physically changed from this test - the originally flexible and clear film became brittle and slightly cloudy.

\section{Conclusions}

The concrete materials demonstrate the most massive degree of water content, outgassing under each experimental condition. The Borobond4 did not change much in appearance, although it was slightly darker in color after heating. However the 277-4 Borated concrete became extremely friable and more sandy than its original texture. It also turned a very light gray color.

The polyethylene film was least likely to hold moisture, but did degrade in each case. This material became glassy and yellowed due to heating, with outgassing observed in the longer duration $338^{\circ} \mathrm{F}$ test. This may result from degradation products, rather than water.

The silicone foam did retain some moisture content over a longer period of time and outgassed at higher temperatures. The silicone elastomer outgas quantity was very small.

Further information about gas composition could be obtained from headspace gas analysis of the captured outgassing products.

Please contact me if you have questions or need more information about this data.

Rosanne A. Smith

576-0615 
Polyethylene $-338^{\circ} \mathrm{F}$ Outgassing $\left(170^{\circ} \mathrm{C}\right)$

(Subtracts a linearly increasing blank outgassing STP volume to $19.2 \mathrm{~cm}^{3}$ )

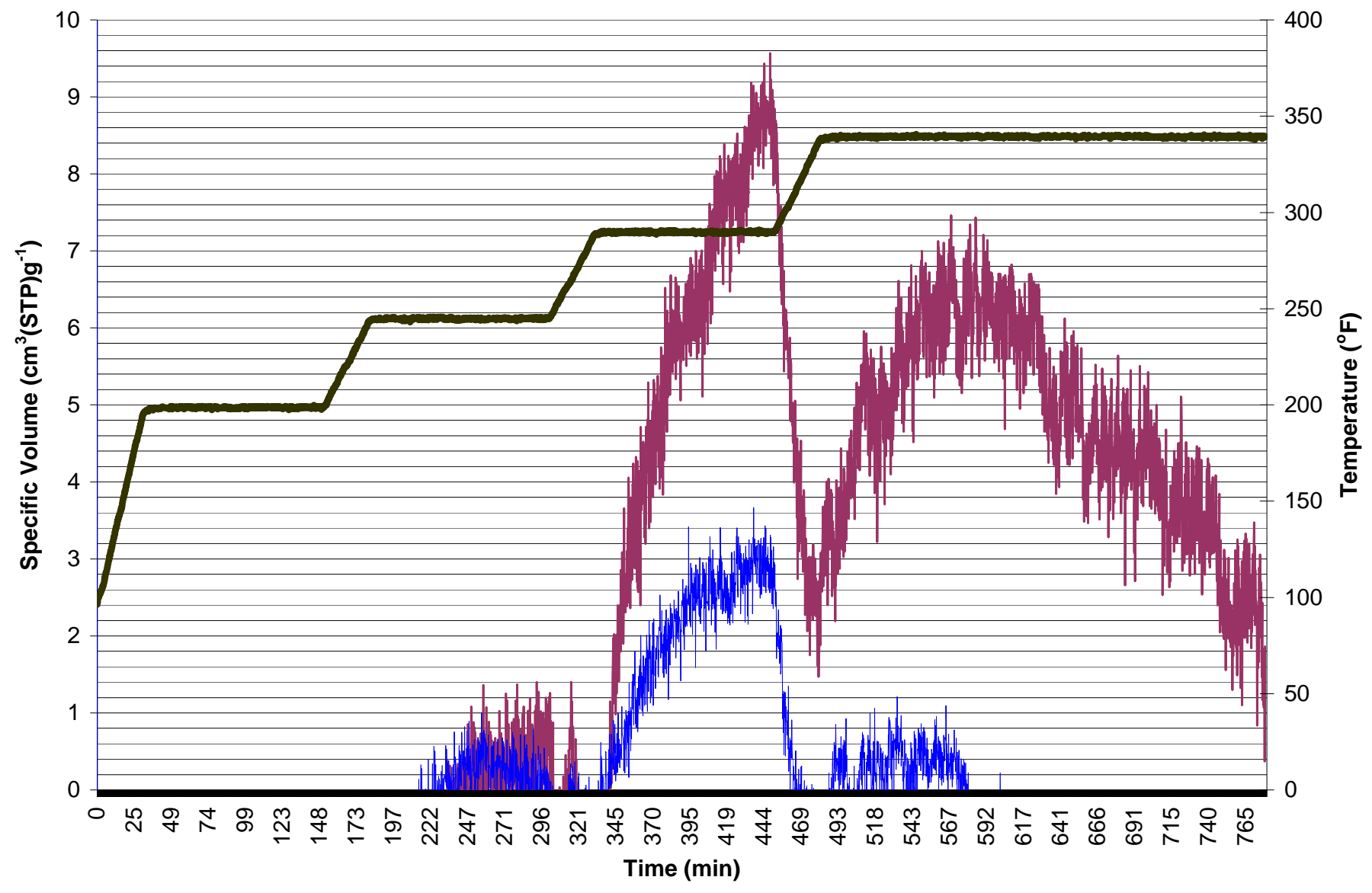

Figure 1. Outgassing of two polyethylene film specimens at 338 degrees F. 
Silicone Foam $-338^{\circ} \mathrm{F}$ Outgassing $\left(170^{\circ} \mathrm{C}\right)$

(Subtracts a linearly increasing blank outgassing STP volume to $19.2 \mathrm{~cm}^{3}$ )

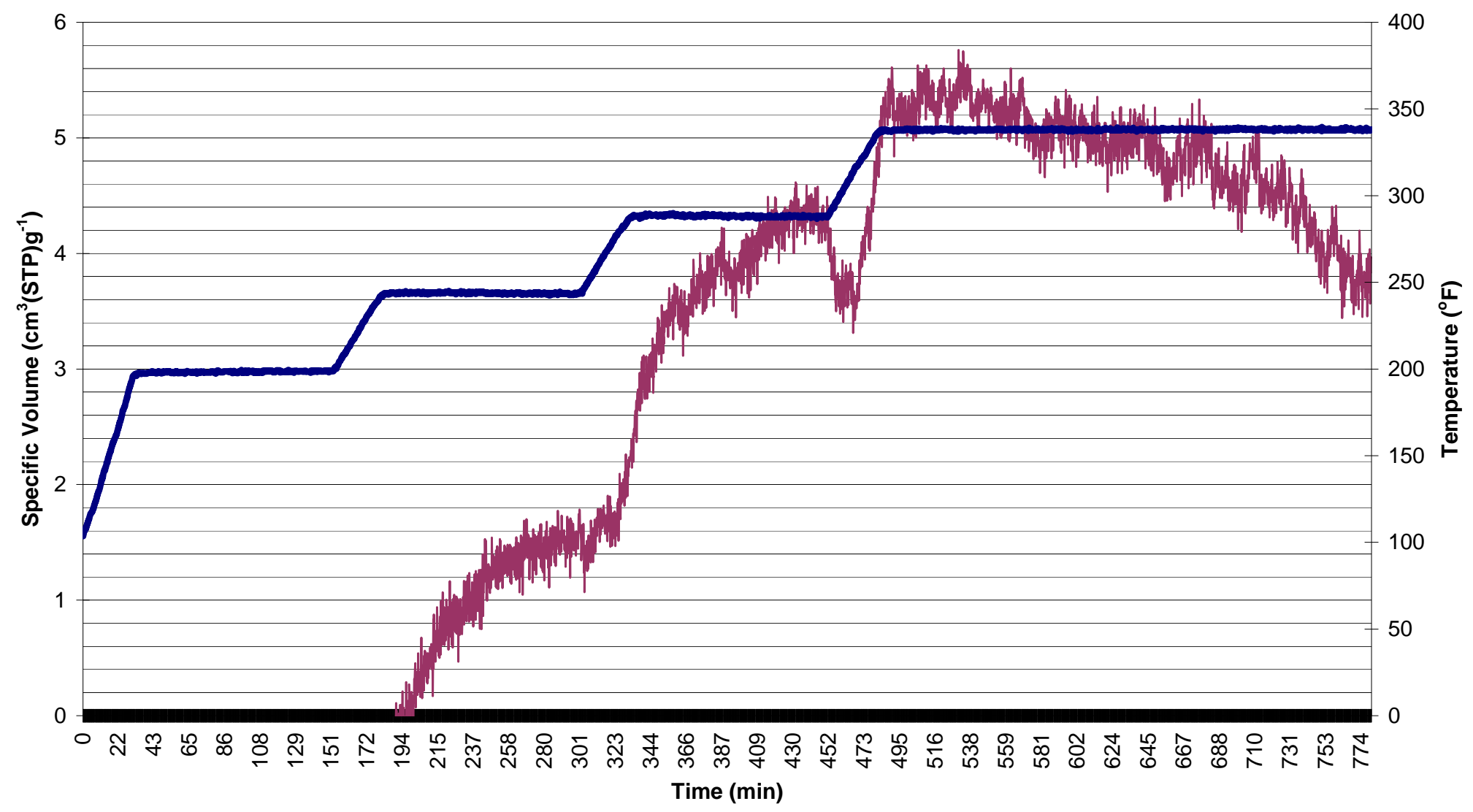

Figure 2. Outgassing of two silicone foam specimens at 338 degrees F. 
Silicone Elastomer $-338^{\circ} \mathrm{F}$ Outgassing $\left(170^{\circ} \mathrm{C}\right)$

(Substracts a linearly increasing blank outgassing STP volume to $19.2 \mathrm{~cm}^{3}$ )

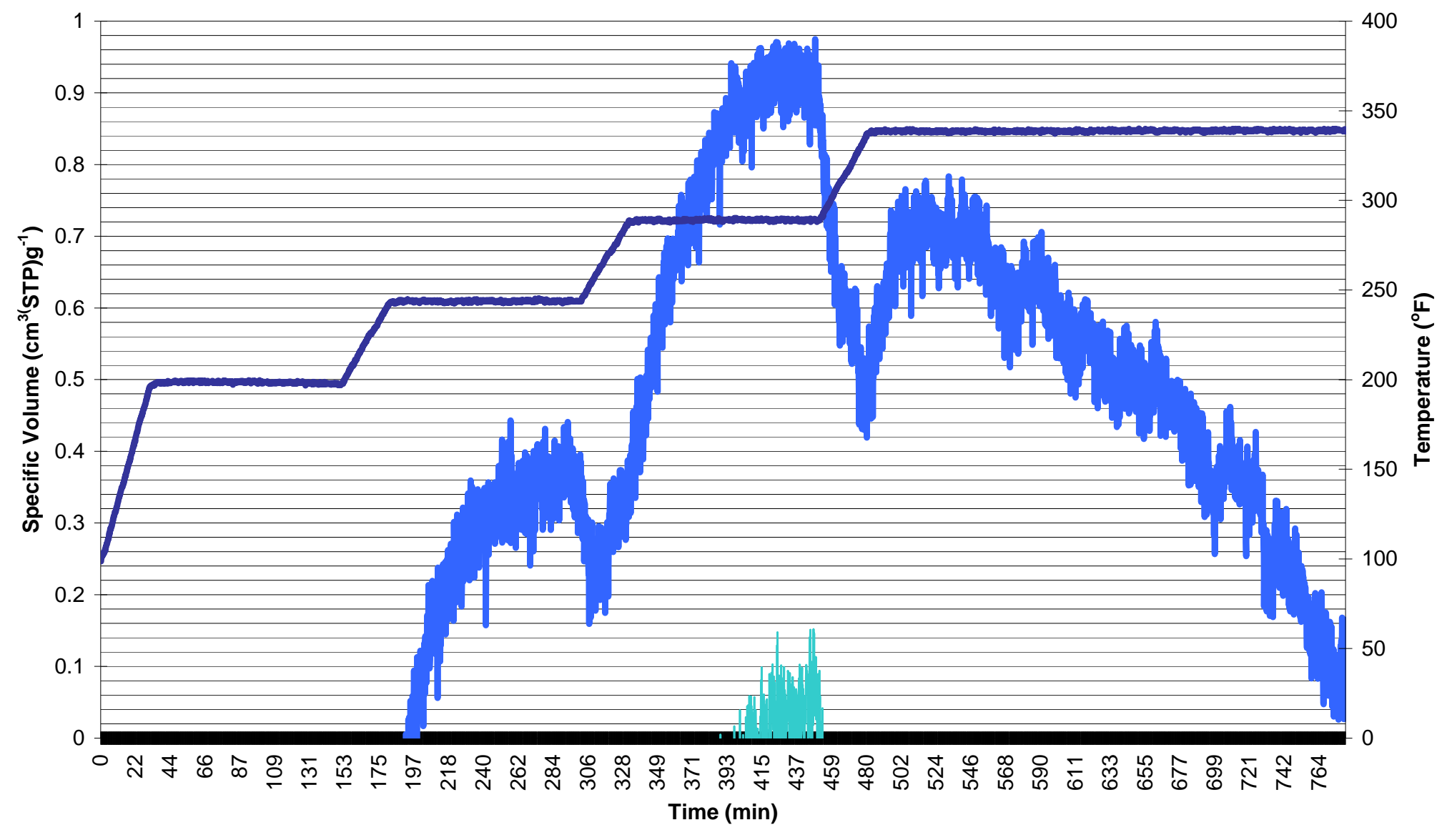

Figure 3. Outgassing of two silicone elastomer specimens at 338 degrees F. 


\section{Borobond4 Concrete $-338^{\circ} \mathrm{F}$ Outgassing $\left(170^{\circ} \mathrm{C}\right)$}

(Subtracts a linearly increasing blank outgassing STP volume to $19.2 \mathrm{~cm}^{3}$ )

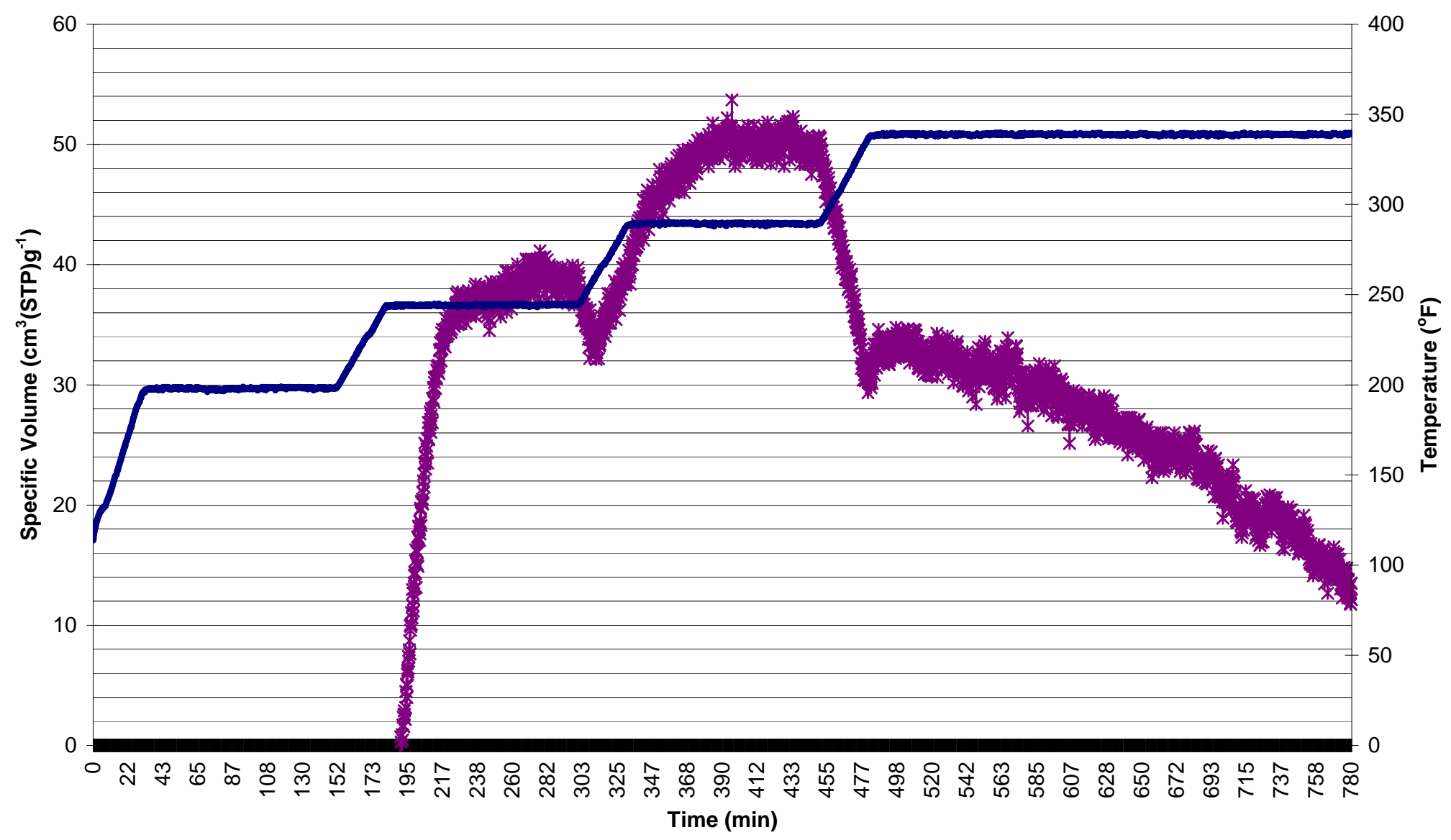

Figure 4. Outgassing of a Borobond4 concrete at 338 degrees F. 
277-4 Borated Concrete $-338^{\circ} \mathrm{F}$ Outgassing $\left(170^{\circ} \mathrm{C}\right)$

(Subtracts a linearly increasing blank outgassing STP volume to $19.2 \mathrm{~cm}^{3}$ )

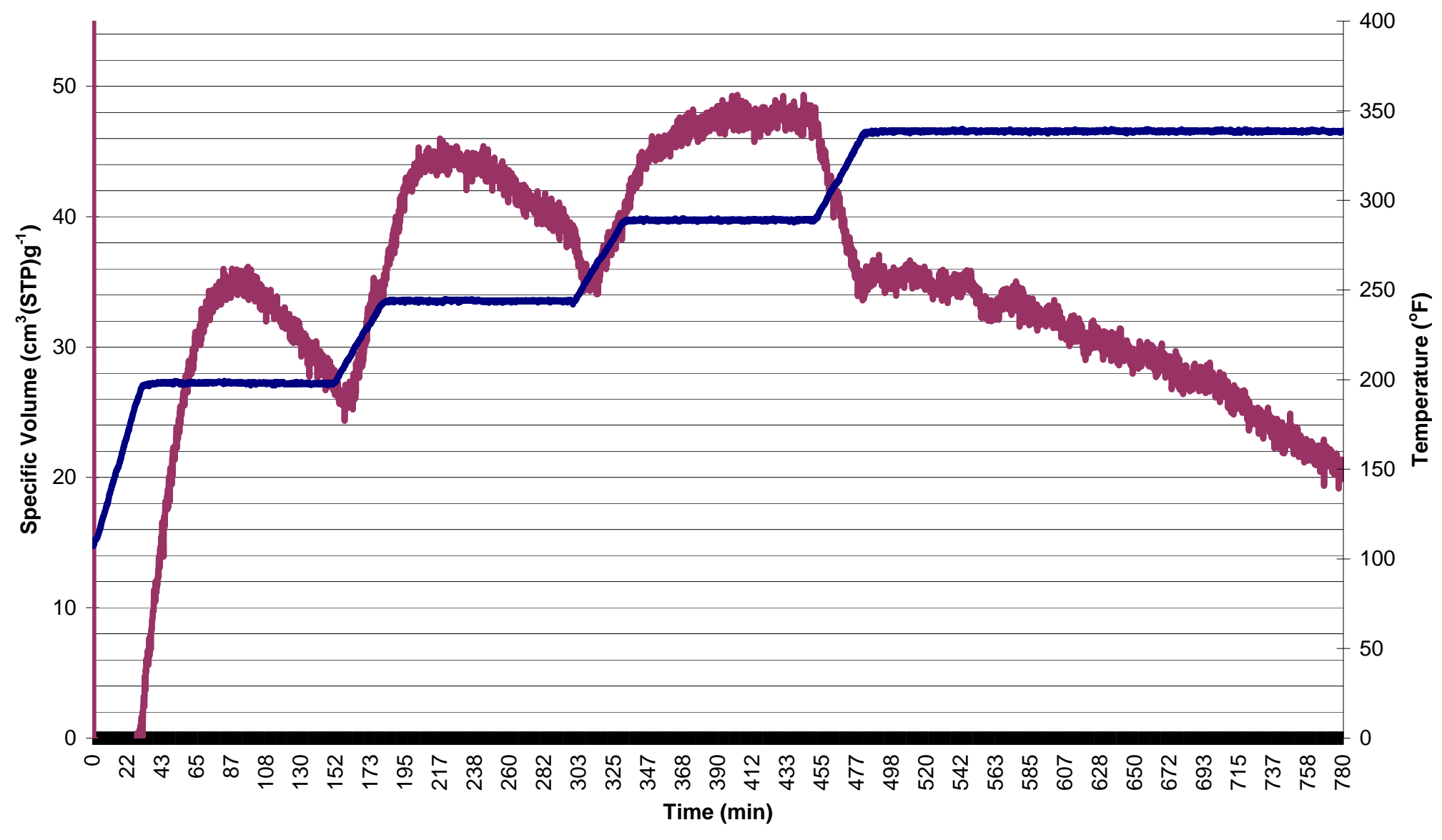

Figure 5. Outgassing of a 277-4 Borated concrete at 338 degrees F. 
Table 1. Outgassing at $180^{\circ} \mathrm{F}$ at standard temperature (298K) and pressure (1 atm).

\begin{tabular}{|c|c|}
\hline Specimen & Quantity (in units $\left.\mathbf{~ c m}^{\mathbf{- 3}}(\mathbf{S T P}) / \mathbf{g}\right)$ \\
\hline Polyethylene -1 & 0 \\
\hline Polyethylene -2 & 0 \\
\hline Silicone Foam -1 & 0 \\
\hline Silicone Foam -2 & 0 \\
\hline Silicone Elastomer -1 & 0 \\
\hline Silicone Elastomer -2 & 0 \\
\hline Borobond4 - 1 & 29.3 \\
\hline Borobond4 - 2 & 32.0 \\
\hline 277-4 Borated Concrete -1 & 20.3 \\
\hline 277-4 Borated Concrete -2 & 46.9 \\
\hline
\end{tabular}

Table 2. Weight Changes in grams after Experiment \#1 $\left(338^{\circ} \mathrm{F}\right.$ or $\left.170^{\circ} \mathrm{C}\right)$.

\begin{tabular}{|l|r|r|r|r|r|}
\hline \multicolumn{1}{|c|}{ Material } & \multicolumn{1}{c|}{ Before } & After & Weight $\Delta$ & \multicolumn{1}{c|}{$\begin{array}{c}\text { Loss } \\
\text { Lostional }\end{array}$} & mol H$_{2} \mathrm{O}^{*}$ \\
\hline borobond4 & 4.04 & 3.35 & 0.69 & 0.17 & 0.038 \\
\hline borobond4 & 1.99 & 1.69 & 0.3 & 0.15 & 0.017 \\
\hline elastomer & 2.38 & 2.38 & 0 & 0.00 & 0.000 \\
\hline elastomer & 1.45 & 1.45 & 0 & 0.00 & 0.000 \\
\hline 277 borated & 4.7 & 3.93 & 0.77 & 0.16 & 0.043 \\
\hline 277 borated & 2.82 & 2.34 & 0.48 & 0.17 & 0.027 \\
\hline polyethylene & 0.26 & 0.26 & 0 & 0.00 & 0.000 \\
\hline polyethylene & 0.19 & 0.2 & -0.01 & $(0.05)$ & $(0.001)$ \\
\hline foam & 0.72 & 0.75 & -0.03 & $(0.04)$ & $(0.002)$ \\
\hline
\end{tabular}


Table 3. Material Information Summary.

\begin{tabular}{|c|c|c|c|c|c|}
\hline Mroperty & $\begin{array}{l}277-4 \text { borated } \\
\text { concrete }\end{array}$ & Borobond4 & Polyethylene & $\begin{array}{c}\text { Silica-filled } \\
\text { polysiloxane } \\
\text { elastomer }\end{array}$ & $\begin{array}{c}\text { Fire-Retardant } \\
\text { Polysiloxane foam }\end{array}$ \\
\hline Composition & Hi-alumina cement & Phosphated cement & LDPE & $\begin{array}{c}\text { Polysiloxane } \\
\text { compression molded } \\
\text { jar seal }\end{array}$ & $\begin{array}{l}\text { Polysiloxane foam with } \\
\text { carbon black }\end{array}$ \\
\hline Application & $\begin{array}{c}\text { Spacers between } \\
\text { HEU parts for } \\
\text { shipping (inside tin } \\
\text { cans) }\end{array}$ & $\begin{array}{l}\text { RT cure and neutron } \\
\text { absorber. This is } \\
\text { baseline material }\end{array}$ & Storage & $\begin{array}{l}\text { Cap for cans; fits on } \\
\text { top of paint cans } \\
\text { used to ship broken } \\
\text { pieces }\end{array}$ & $\begin{array}{l}\text { Liner materials to } \\
\text { cushion impact }\end{array}$ \\
\hline Appearance & $\begin{array}{l}\text { 2”x2” block of gray } \\
\text { ceramic-looking } \\
\text { solid. Porous } \\
\text { appearance }\end{array}$ & $\begin{array}{l}\text { 2”x2” block of dark } \\
\text { gray metallic-looking } \\
\text { solid. Very hard }\end{array}$ & $\begin{array}{l}\text { Clear plastic bags } \\
\text { as in "zip-loc" }\end{array}$ & $\begin{array}{c}\text { Dark gray } \\
\text { elastomeric pliable } \\
\text { ring }\end{array}$ & $\begin{array}{l}\text { Medium gray smooth } \\
\text { skinned small-celled } \\
\text { foam, soft with } \\
\text { adhesive backed paper }\end{array}$ \\
\hline Amount received & $203.30 \mathrm{~g}$ & $259.36 \mathrm{~g}$ & 2 bags $=32.95 \mathrm{~g}$ & $38.37 \mathrm{~g}$ & $5.95 \mathrm{~g}$ \\
\hline
\end{tabular}

**Density data not measured - for reference only. 